\title{
A Historical Review of Slope Based SCS Method and its Effect on CN and Runoff Potential Globally
}

\author{
Tauseef Ahmad Ansari ${ }^{1}$; Y.B. Katpatal ${ }^{2}$; C. Rishma ${ }^{3}$ \\ sirftauseef@gmail.com, ybkatpatal@ rediffmail.com, rishma.chengot@cranfield.ac.uk \\ University of Buraimi, Oman. \\ Visvesvaraya National Institute of Technology, Nagpur, India. \\ Cranfield University, United Kingdom.
}

\begin{abstract}
The Soil Conservation Service - Curve Number (SCS-CN) method is extensively used to calculate the runoff from rainfall over a large catchment over the world. Slope is an important criterion for runoff but a very few attempts have been made to evaluate the effect of slope on the $\mathrm{CN}$ with runoff potential. The objective of this paper is to summarise the historical review on the effects of slope on $\mathrm{CN}$ and runoff potential in various regions by the hydrologists. This paper also depicts that how the various researchers proved the importance of consideration of slope for $\mathrm{CN}$ and runoff estimation. In addition, paper highlights the key features of research in future like to classify the watersheds on slope based $\mathrm{CN}$, accurate Antecedent Moisture Condition (AMC) and proper initial abstraction in the various regions etc. Considering these parameters an accurate runoff estimation can be predicted and managed properly in the urban watersheds.
\end{abstract}

Keywords: Slope based SCS Curve Number; Antecedent Moisture Condition; Land Use; Runoff potential; Urban watersheds.

Introduction: Various methods are used for runoff estimation and the Soil Conservation Service (SCS) is also one of them. The Soil Conservation Service Curve Number (SCS-CN) method was developed in 1954 and is documented in Section 4 of the National Engineering Handbook-4 (NEH-4) published by the Soil Conservation Service (now called the Natural Resources Conservation Service), United State Department of Agriculture in 1956. The document has since been revised in 1964, 1965, 1971, 1972, 1985, and 1993 [1].The Curve Number $(\mathrm{CN})$ method is widely used globally for predicting the surface runoff from rainfall. It is also called as Natural Resource Conservation Service Curve Number (NRCS-CN) method [2]. The SCS-CN method is an empirical equation predicting runoff from rainfall, considering the various parameter like soil, vegetation, land use, and soil moisture prior to a rainfall event [2]. $\mathrm{CN}$ is actually a dimensionless number which varies from 0 to 100 , where 0 indicates no runoff while 100 specifies very good runoff generation. It is used extensively in various hydrologic, erosion, and water-quality models, including CREAMS etc [3].

A review of the existing literature shows that various investigations have been conducted to evaluate the effect of the slope on CN and runoff potential. For example, in 1990, Sharpley and William integrated slope for determining the runoff depth in the regular method and adjusted $\mathrm{CN}_{2}$ for slope. Similarly, Huang et al. [4] studied the effect of slope on runoff in China and proposed a simplified equation for slope as $\mathrm{CN}_{2} \alpha$ but slope ranging from 14 to 140 
$\%$. Hence, the literature provides brief summary of the earlier research outcomes and the developments related to the slope based SCS-CN. The objective of this paper is to review the researches including the effect of slope on $\mathrm{CN}$ and runoff in various watersheds all over the world.

\section{Basics of Soil Conservation Service Curve Number (SCS-CN) Equation:}

The SCS CN is based on the water balance where two hypothesis (ratio of actual amount of direct runoff to the total rainfall and actual infiltration to the potential maximum retention) are equated to form the equation. The equation (1) is the basic equation of SCS CN.

$$
\begin{gathered}
\mathrm{Q}=\frac{(P-I a)^{\wedge} 2}{(P-I a+S)} \text { for } \mathrm{P}>\mathrm{Ia} \ldots \ldots(1) \\
\mathrm{Q}=0 \quad \text { for } \mathrm{P} \leq \mathrm{Ia}
\end{gathered}
$$

Where, $\mathrm{Q}$ is surface runoff $(\mathrm{mm}), \mathrm{P}$ is rainfall $(\mathrm{mm}), \mathrm{Ia}=\mathrm{Initial}$ abstraction $(\mathrm{Ia}=0.2 \mathrm{~S})$ and $\mathrm{S}$ is the retention parameter $(\mathrm{mm})$. The value of $\mathrm{S}$ is obtained from the given below equation (2)

$$
\mathrm{S}=\frac{25400}{\mathrm{CN}}-254
$$

Where, $\mathrm{CN}$ varies from 0 to 100 . The $\mathrm{CN}$ value is determined based on land cover and hydrologic soil group using a table given by the SCS handbook [2].

\section{The historical background of effect of slope on $\mathrm{CN}$ with runoff potential:}

In the present study, related peer reviewed journals have been referred which take into consideration the effect of slope on $\mathrm{CN}$ and runoff estimation. In literature survey, it is found that very few studies are available which account the effect of slope on $\mathrm{CN}$ and runoff. This concept was started by the Sharpley and Williams [5], who adjusted the CN for moisture condition 2 (Average moisture condition) called as $\mathrm{CN}_{2}$ upto $5 \%$ slope and proposed an equation (3).

$$
\mathrm{CN}_{2 \mathrm{~S}}=1 / 3\left(\mathrm{CN}_{3}-\mathrm{CN}_{2}\right)\left[1-2 \mathrm{e}^{(-13.86 \mathrm{~S})}\right]+\mathrm{CN}_{2}
$$

After Sharpley and Williams, Huang et al. [4], performed an experiment over $0.25 \mathrm{~km}^{2}$ watershed with varying slope of range $17 \%$ to $140 \%$ with vegetation cover at Xifeng in the Loess Plateau of China. The annual rainfall in the area was observed $562 \mathrm{~mm}$ in last 44 years with average annual temperature of $10^{\circ} \mathrm{C}$ and $890 \mathrm{~mm}$ potential evaporation. It was found that calculated mean runoff depth and $\mathrm{CN}$ values, increases with slope. A relationship between slope, observed and theoretical $\mathrm{CN}$ values was developed in the form of an equation to predict 
better runoff depth which appeared more appropriate. Ponce et al. [6], critically examined the review paper on the maturity of SCS-CN method. They determined its capabilities, limitations and uses and also identified the various areas of research in SCS-CN method. This paper pointed out that the SCS-CN method does not take into account the spatial and temporal variability of infiltration and other abstractive losses. It aggregates these into a calculation of the total depth loss for a given storm event and drainage area.

Similarly, Ebrahimian et al. [7], carried out the study in Kardeh watershed in northeast Iran. It is found that for 9 and $6 \%$ slopes estimated and adjusted runoff values were $\pm 10 \%$ of the recorded values, respectively. Similarly 43 and $37 \%$ of the estimated and slope adjusted values of runoff were different $\pm 50 \%$ of the recorded values. While the slope adjusted $\mathrm{CN}$ equation was found appropriate for runoff estimation in steep slope watersheds. Hence it was found that the standard $\mathrm{CN}$ method can be used with 55\% accuracy in steep slope watersheds. After that Garg et al.[8], evaluated the runoff depth considering slope for 81 rain events in sub watershed (SW) of Ganga basin using NRCS-CN method. The results from ANOVA showed that there was significant decrease in runoff depth values estimated from normal Curve Number $(\mathrm{CN})$ compared to slope based Curve Number $\left(\mathrm{CN}_{2}\right)$. Also, the values of runoff depth using slope $\left(\mathrm{CN}_{2}\right)$ method is found more than the normal curve $\mathrm{CN}$ for each watershed (Sharpley and Williams and Huang approaches).

In the same year, Siavash et al.[9], selected the coal mining region of the southern Appalachians in U.S.A., and studied over three active surface-mine sites in East Tennessee. Rainfall runoff was monitored during one year for 5-min intervals using a unique Pinson-type collection system. CNs were calculated by the traditional NEH-4 (Part 630) method and two asymptotic frequency-matching techniques. CNs generated by the NEH-4 method among all three mining sites were not significantly different suggesting common shale-based loose spoils on steep slopes have similar runoff behaviour.

Deshmukh et al. [10], selected Barureva, Sher and Umar watershed as study area located in Narmada basin. The experiment was performed over three different types of land use considering slope for the years 1972, 1989 and 2000 using SCS CN method. Following results were found in their research.

i) Slope based $\mathrm{CN}\left(\mathrm{SA}-\mathrm{CN}_{2}\right)$ is less than the normal CN (SCS-CN) when slope is less than 5 $\%$ but it is more than SCS-CN when slope is greater than 5\%. Higher the deviation from 5\% slope more is the difference.

ii) Significant changes in $\mathrm{CN}$ values were observed in slope based forest land. 
iii) Effect of slope on $\mathrm{CN}$ is relatively less significant in watersheds having agriculture and other land use and land covers.

iv) For micro watershed planning, $\mathrm{CN}$ method can be modified considering land use with slope effect.

Sai et al. [11], simulated rainfall and runoff to estimate the CN over various types of slope combined with different kind of materials for highways. He has taken two soil-turf combinations with Argentine Bahia over AASHTO A-3 soil (fine sand) and Pensacola Bahia over AASHTO A-2-4 soil (silty fine sand). The $\mathrm{CN}$ values for Argentine Bahia A-3 soil combination was found in range 70.4 to 93.0 with a mean value of 79.6. The $\mathrm{CN}$ values for Pensacola Bahia A-2-4 soil combination was found in range 89.0 to 97.2 with a mean of 94.0. It was also observed that the $\mathrm{CN}$ values increased with an increase in slope, but there was a mixed pattern with increasing rainfall intensity.

Mishra et al. [1], performed an experiment over a plot of size $22 \mathrm{~m}$ x $5 \mathrm{~m}$ considering slope with land use of maize and sugarcane on the soil falling in Hydrologic Soil Group C) located in Roorkee, India. The results of the experiments shows that the runoff increases, as the slope increases. The mean runoff was $29.42 \%$ of the rainfall amount for $1 \%$ slope, 34.07 $\%$ for $3 \%$, and $48.52 \%$ for $5 \%$ slope for sugarcane; and $24.66 \%, 40.58 \%, 51.53 \%$ for maize, respectively. The results also shows the difference between the $\mathrm{CN}$ estimated from traditional method and slope based CN. The error in $\mathrm{CN}$ was $1.73 \%$ for $1 \%$ slope, $0.327 \%$ for $3 \%$ slope for maize; and $1.68 \%$ for $1 \%$ slope, $0.605 \%$ for $3 \%$ slope for sugarcane. The error however reduced to zero for $5 \%$ slope for both land uses, as original SCS-CN method which computes the $\mathrm{CN}$ correspond to $5 \%$ slope.

Abolghasem [12], adjusted the CN for modified SCS method using Advanced Space borne Thermal Emission and Reflection Radiometer (ASTER) Global Digital Elevation Model (GDEM) for Kuantan River Basin (KRB). It was found that the adjustment for new initial abstraction lead to decrease the $\mathrm{CN}_{0.05 I I}(\mathrm{CN}$ at $5 \%)$ values specifically for smaller $\mathrm{CN}_{0.2 \mathrm{II}}(\mathrm{CN}$ at 20\%). He also found that the Sharply-Williams (1990) and Hung method (2006) improve the spatial variation of $\mathrm{CN}$ over the basin. Considering the standard values of $\mathrm{CN}$, both methods are unable to limit the domain of the $\mathrm{CN}$ in standard domain which 0-100.

Muhammad et al. [13], estimated the runoff using NRCS slope adjusted CN method in the mountainous watershed of South Korea. This study investigated two existing approaches of $\mathrm{CN}$ estimation and suggested a new approach. It is found that the steepness of the slope of watershed is the dominant factor to generate the runoff as compared to the plain areas or having slope less than or equal to 5\%. It is also found that NRCS method using $\mathrm{CN}_{2}$ values was found 
to be least efficient model for runoff estimation because of very small difference between the $\mathrm{CN}_{2}$ and $\mathrm{CN}_{2} \alpha$ while in Huang [4] method, improved runoff estimation was observed. The newly proposed $\mathrm{CN}_{2} \alpha$ approach is more reliable than the $\mathrm{CN}_{2}$.

Tauseef et al. [14], investigated the effect of slope on CN and runoff. In the study, it is found that weighted $\mathrm{CN}$ is marginally increased for all watersheds due to slope. It is also found that when slope is considered to estimate the runoff using Sharpley and William model, the runoff volumes has also increased. This study also depicts that the increase in Impervious Surface Area (ISA) has more impact on runoff volume than the slope.

Sangeeta et al. [15], analysed that when SCS-CN model is coupled with slope, increase in runoff is observed. It was also observed that the Sharpley and Williams [14] approach of slope adjustment for $\lambda$ (ratio of initial abstraction to the infiltration) value equal to 0.3 performed the best with lowest RMSE (10.88) and highest $\mathrm{R}^{2}(0.8757)$. In addition, the performance of all models decreases as $\lambda$ value decreases.

Muhammad et al. [16] analysed a very important factor which is still in debate among the researchers that what should be the value of $\lambda$ and slope of the watersheds to estimate the accurate runoff. They proposed a slope adjusted $\mathrm{CN}\left(\mathrm{CN}_{2} \alpha\right)$ to improve the runoff prediction capability of $\mathrm{CN}$ model in steep slope. It is also proposed that value of $\lambda=0.05$ in place of $\lambda=$ 0.2 improves result of the proposed model. The fixed value of $\lambda(\lambda=0.2)$ has limitation because of diversity of land use and soil characteristics.

\section{Conclusions:}

After the literature review, it is found that instead of being a very important parameter, very few scientists have touched the slope based CN in the last 30 years. The SCS-CN (currently NRCS-CN) method has the advantages over other methods like its simplicity, predictability and used for large areas. This method is rainfall event based method rather than single annual rainfall value but still it has a more scope of research to reconsider the following parameters of the SCS-CN methods.

i) It requires more research in the steep slope (mountain) regions especially in the spatial and temporal changing pattern of land use like urban area and also in ungauged watersheds.

ii) When slope of the watersheds are more than 5\% (mountains watershed) then it is very important to consider the effects of slope because it affects $\mathrm{CN}$ and runoff values.

iii) The modified $\mathrm{CN}$ model can be proposed and also the estimated and observed $\mathrm{CN}$ values can be validated for different urban areas. 
iv) $\mathrm{CN}$ method requires to monitor regularly the changes occurring in spatial and temporal pattern of land use in an urban area. Impervious Surface Areas (ISA) due to which CN values increases and generates more amount of runoff in result flash floods occur.

v) Antecedent Moisture Condition (AMC) of 5 days requires more research before runoff calculation because of its sensitivity. It can underestimate or overestimate the runoff values.

vi) According to the literature, Initial abstraction $(\mathrm{Ia}=0.2 \mathrm{~S})$ is also very sensitive parameter while estimating the runoff hence, it has a huge scope of research for SCS-CN method because its values $(\mathrm{Ia}=0.05 \mathrm{~S})$ varies in urban watersheds.

\section{References:}

[1] Mishra S.K., Singh V.P. (2003) SCS-CN Method. In: Soil Conservation Service Curve Number (SCS-CN) Methodology. Water Science and Technology Library, vol 42. Springer, Dordrecht. https://doi.org/10.1007/978-94-017-0147-1_2

[2] S.C.S. (1972) National Engineering Handbook, Section 4. Hydrology, Soil Conservation Service, US Department of Agriculture: Washington, DC.

[3] Knisel W.G. 1980. CREAMS: a field-scale model for chemical, runoff and erosion from agricultural management systems. Conservation Research Report No. 26, South East Area, US Department of Agriculture, Washington, DC.

[4] Huang Mingbin, Jacques Gallichand, Zhanli Wang, Monique Goulet (2006) A modification to the Soil Conservation Service curve number method for steep slopes in the Loess Plateau of China. Hydrological Process. 20, 579-589.

[5] Sharpley A.N., Williams J.R. (1990) EPIC-erosion/productivity impact calculator: 1. Model determination. U.S. Department of Agriculture. Tech. Bull., No. 1768.

[6] Ponce V.M., Hawkins R.H. (1996) Runoff curve number: has it reached maturity? J Hydrol Eng ASCE 1:11-19.

[7] Ebrahimian M., Nurruddin A.A.B., Soom M.A.B., Sood A.B., Neng L.G. (2012) Runoff estimation in steep slope watershed with standard and slope adjusted curve number methods. Pol J Environ Stud 21(5):1191-1202.

[8] Garg V., Nikarn B.R., Thakur P.K., Aggarwal S.P. (2013) Assessment of the effect of slope on runoff potential of a watershed using NRCS-CN method. Int J Hydrol Sci Technol 3(2):141-159.

[9] Siavash Hoomehr, John S. Schwartz, Daniel C. Yoder, Eric C. Drumm and Wesley Wright (2013) Curve Numbers for Low-Compaction Steep-Sloped Reclaimed Mine Lands in the Southern Appalachians. J. Hydrol. Eng.18:1627-1638. 
[10] Deshmukh D.S., U.C. Chaube, Ambaye Ekube, Dida Aberra, Melaku Tegene (2013) Estimation and Comparision of Curve Numbers Based on Dynamic Land use Land Cover Change, Observed Rainfall-Runoff Data and Land Slope. Journal of Hydrology,doi: http://dx.doi.org/10.1016/j.jhydrol.2013.04.001.

[11] Sai P. Kakuturu, Manoj B. Chopra, Mike Hardin and Martin P. Wanielista (2013) Runoff Curve Numbers for Simulated Highway Slopes under Different Slope, Soil-Turf, and Rainfall Conditions. J. Hydrol. Eng.18:299-306.

[12] Abolghasem Akbari (2015) Slope adjustment of runoff curve number (CN) using Advanced Spaceborne Thermal Emission and Reflection Radiometer (ASTER) Global Digital Elevation Model (GDEM) for Kuantan River Basin. Proc. of SPIE Vol. 9644 96441W-1.

[13] Muhammad Ajmal, Muhammad Waseem, Jae-Hyun Ahn, and Tae-Woong Kim (2016) Runoff Estimation Using the NRCS Slope-Adjusted Curve Number in Mountainous Watersheds. J. Irrig. Drain Eng., 04016002.

[14] Tauseef Ahmad Ansari, Yashwant B. Katpatal, A. D. Vasudeo (2016) Spatial evaluation of impacts of increase in impervious surface area on SCS-CN and runoff in Nagpur urban watersheds, India. Arab J Geosci. 9: 702 DOI 10.1007/s12517-016-2702-5.

[15] Sangeeta Verma, Anju Singh, Surendra K. Mishra, Pushpendra K. Singh, Ravindra K. Verma (2018) Efficacy of slope-adjusted curve number models with varying initial abstraction coefficient for runoff estimation Int. J. Hydrology Science and Technology, Vol. 8, No. 4, 2018

[16] Muhammad Ajmal, Muhammad Waseem, Dongwook Kim and Tae-Woong Kim (2020) A Pragmatic Slope-Adjusted Curve Number Model to Reduce Uncertainty in Predicting Flood Runo_from Steep Watersheds. Water 2020, 12, 1469; doi: 10.3390/w12051469. 